\title{
The Impact of Environmental Stimuli on Hotel Service Employees' Service Sabotage-Mediation Role of Emotional Intelligence and Emotional Dissonance
}

\author{
Habib Alipour ${ }^{1, *} \mathbb{C}$, Shahrzad Amelshahbaz ${ }^{1}$, Farzad Safaeimanesh $^{1} \mathbb{C}$, Bahman Peyravi $^{2}$ and Alireza Salavati $^{3}$ \\ 1 Faculty of Tourism, Eastern Mediterranean University, 99450 Famagusta, Turkey; \\ shahbazshahrzad8@gmail.com (S.A.); safaeimanesh@emu.edu.tr (F.S.) \\ 2 Faculty of Business Management, Vilnius Gedimino Technical University, Sauletekio al. 11, \\ 10223 Vilnius, Lithuania; bahman.payravi@gmil.com \\ 3 Aberystwyth Business School, Penglais Campus, Aberystwyth University, Aberystwyth, \\ Ceredigion SY23 3FL, UK; alireza.salavati@gmail.com \\ * Correspondence: habib.alipour@emu.edu.tr; Tel.: +90-392-630-1392
}

Citation: Alipour, H.; Amelshahbaz, S.; Safaeimanesh, F.; Peyravi, B.; Salavati, A. The Impact of Environmental Stimuli on Hotel Service Employees' Service Sabotage-Mediation Role of Emotional Intelligence and Emotional Dissonance. Sustainability 2021, 13, 876. https://doi.org/10.3390/ su13020876

Received: 30 December 2020 Accepted: 12 January 2021 Published: 16 January 2021

Publisher's Note: MDPI stays neutral with regard to jurisdictional clai$\mathrm{ms}$ in published maps and institutional affiliations.

Copyright: (C) 2021 by the authors. Licensee MDPI, Basel, Switzerland. This article is an open access article distributed under the terms and conditions of the Creative Commons Attribution (CC BY) license (https:// creativecommons.org/licenses/by/ $4.0 /)$.

\begin{abstract}
While scholarly inquiries into Service Sabotage (SS) have received ample attention in the literature of various industries, the role of Emotional Intelligence (EI) and Emotional Dissonance (ED) in employee-customer relations in the context of Environmental Stimuli (ES) in the tourism accommodation sector has remained unexplored. The role of employee-customer interaction in tourism is paramount for a hospitality organization's growth, sustainability, and profitability. We hypothesized hotel service employees' EI and ED can be influential factors to SS. Adopting the Mehrabian-Russell model (M-R) and Stimulus-Organism-Response (S-O-R) framework as conceptual paradigms, we tested the effect of hotel ambiance on employees' emotions, which can have significant effects on SS. The study revealed that ES links to behaviors and elicits EI and ED as human emotional responses to environments that have a parallel mediating effect on mitigating or neutralizing the negative effect of SS in an organization. The findings provide important insights into an organization's awareness of the provision of ES as a positive factor for employees, subsequently forming their behavioral consequences of EI and ED which can mitigate the negative impacts of SS. The study yields important implications on how hospitality organizations should pay attention to the impact of rule-breaking behaviors. Theoretical and practical implications are also discussed.
\end{abstract}

Keywords: tourism accommodation; emotional intelligence; emotional dissonance; service employees; service sabotage; north Cyprus

\section{Introduction}

In the globally competitive hospitality and tourism sector, it is important to investigate and learn the emotional/behavioral responses of service employees in relation to working ambiance with the aim of enhancing loyalty/satisfaction, sustainability, and profitability in the organization [1-5]. Particularly in the labor-intensive tourism and hospitality sector where the service encounter is fundamental. Service employees play a pivotal role as they have constant service encounters with customers [6,7]. "As part of their daily work, hospitality employees need to interact with others, essentially the customers. During these interactions, the employees have to perform emotional labor, which is referred to as the management of feeling to create a publicly observable facial and bodily display" (as cited in Xu et al., 2020 [8] (p. 1).

One of the core aspects of organizational psychology revolves around the nature of the interaction between employees and customers, which has drawn the attention of policymakers to the sustenance of employee emotional well-being [3,9]. There is an ample number of studies on environmental stimuli (i.e., atmospheric/ambiance) on consumer 
emotions and behavior [10-14] however, there are limited empirical studies on exploring the effects of workplace attributes on the emotions and behavior of service employees in the tourism and hospitality sector, specifically, in hotels. To the authors' best knowledge, this is the first study that tests the effects of environmental stimuli/ambiance (i.e., air quality, temperature, humidity/dryness, aroma/scent, background music, noise, etc.) on employee emotional behavior (i.e., emotional intelligence and emotional dissonance) and the consequential implications for service sabotage. 'Service sabotage occurs when a customer-contact employee knowingly acts in a manner that disrupts an otherwise satisfactory service encounter' [7] (p. 326). The assumption is that service employees are susceptible to ambiance attributes that can trigger emotional intelligence (positive behavior) or emotional dissonance (negative behavior) [1,15]. Kwak et al. (2018) wrote, 'emotional dissonance is considered the negative product of emotional labor [1] (p. 228). Schreuder et al. (2016) observed, 'how we perceive our environment affects the way we feel and behave [11] (p. 1). The impressions of our ambient environment are influenced by its entire spectrum of physical characteristics (e.g., luminosity, sound, scents, [and] temperature) in a dynamic and interactive way'.

Emotional intelligence, on the other hand, signifies positive response behavior through environmental stimuli that elicits 'pleasure' (affective emotional responses) [14-17], which discourages service sabotage.

Service employees who are in constant service encounter in the tourism and hospitality sector can view their work as repetitive, unfulfilling, monotonous, and often mindnumbingly boring, and are situated in a low paid sector with long working hours $[7,18]$. Humborstad et al. (2007) argue that it is the responsibility of managers to provide an organizational environment as part of the internal cultural effort toward a favorable working ambient to cultivate commitment instead of inadvertently facilitating service sabotage [18].

This study then draws on Mehrabian and Russell's Environmental Psychology model [19], as well as a Stimulus-Organism-Response (S-O-R) framework $[14,20,21]$ to explain the effects of environmental variables on service employees' emotional states and ultimately their behavior towards customers with implications for service sabotage. Notwithstanding the substantial amount of studies on the impact of the physical environment on human psychology and behavior, previous research has been limited to particular elements in the physical environment (e.g., lighting and music), nonetheless, a combined effect of several physical environmental elements in the tourism and hospitality sector remains under-researched. Steg et al. (2014) elaborated on this gap, not necessarily on tourism, but analyzing environmental behavior as the strength of normative goals depends on individual factors (in particular biospheric values), as well as situational factors (that is, situational cues that activate or deactivate different types of values) that are generally overlooked in environmental behavior research' [20] (p. 105). The main objectives of the current study are (i) to adapt the Mehrabian-Russell models (i.e., M-R and S-O-R) to a hotel ambient context (i.e., service employees working area and reception counter) and (ii) to investigate the impact of ambiance characteristics (e.g., air quality, temperature, humidity, odor, music, etc.) on emotional behavior (emotional intelligence and emotional dissonance). (iii), to examine the effect of emotional behavior towards service sabotage.

\section{Conceptual Framework}

The relationship between physical environment (i.e., servicescape) $[5,21]$ and service providers' (i.e., service employees) response behavior during a service encounter can be analyzed and explained in the context of environmental psychology as elaborated and theorized by Mehrabian-Russell' model [19]. In the context of environmental psychology, the Mehrabian-Russell model has become an epistemological platform to investigate and analyze the physical environmental impact on people. 'Mehrabian and Russell introduced pleasure, arousal and dominance as three independent emotional dimensions to describe people's state of feeling' [22] (p. 406) (see also Figure 1). 


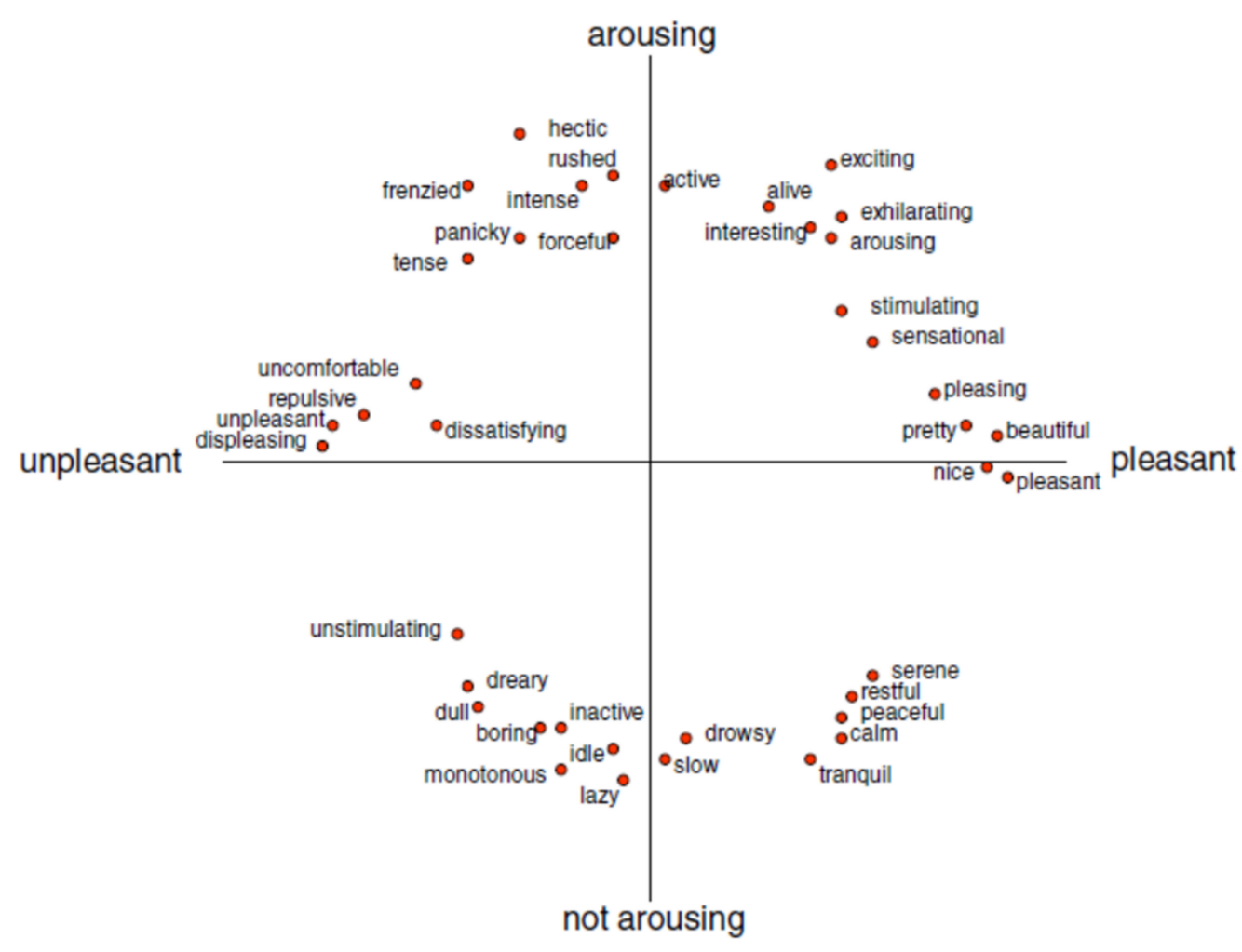

Figure 1. Example of an environmental psychology model. Source: As cited in Bakker et al. [22] (p. 456).

The Mehrabian-Russell model has been utilized in various studies, mainly in marketing and consumer behavior research [12,14,23,24]. Morrison et al. (2011) found that their 'conceptualization predicts that in a retail fashion store focusing on the female youth market loud music and a pleasant (vanilla) aroma will significantly and independently impact shoppers' pleasure and arousal' [14] (p. 562). Mehrabian and Russell described pleasure purely in terms of positive or negative feelings [19]. Service employees' feelings and their response behavior during the service encounter can be contextualized in the environmental characteristics of the working environment. For instance, 'luminosity of light sources, the nature and level of ambient noise and acoustics, the presence of specific odors, color hues, and shades, and materials and atmospheric factors such as temperature and humidity, all generate sensory input, and combined contribute to specific reactions in the observer' (as cited in Schreuder et al., 2016 [11] (p. 2).

Mehrabian and Russell (1974) have also introduced the Stimuli-Organism-Response (S-O-R) model, which was adjusted by Bitner (1992) and Lin (2004) under the servicescape framework $[19,25,26]$. 'In this model, the environmental stimuli (S) first evokes an emotional response in individuals $(\mathrm{O})$, which, in turn, potentially elicits either approach or avoidance behavior (R)' [11] (p. 3). Jani and Han (2015) have applied this model to examine hotel ambiance and its impact on guests and how it can affect loyalty through the mediation effect of consumption emotions (i.e., positive or negative) [12]. Nevertheless, 'the relevance of emotional variables is already supported in the Stimulus-Organism-Response (S-O-R) paradigm and the atmosphere and servicescape models' (as cited in Errajaa et al., 2018 [27] (p. 102). This has been highlighted by Mehrabian-Russell models [19], which suggests that environmental stimuli (ambient characteristics) can result in internal reactions (e.g., emotional intelligence and emotional dissonance) and thus, in turn, induces a response behavior/reaction (e.g., pleasant or unpleasant) with consequences towards avoiding service sabotage or acting upon it.

Our study is an attempt to fill the gap in the knowledge by integrating hotel ambiance and service employee response to service sabotage by contextualizing the mediating effects 
of emotional intelligence and emotional dissonance. Notwithstanding the volume of research regarding emotional exultation, the impact of the workplace environment and its impact on employee emotional behavior and its influence on service sabotage as well as job performance remain unexplored [28]. The review of Emotional Intelligence (EI) and Emotional Dissonance (ED) and their mediating effect in relation to ambient characteristics, especially pertinent to service employees in the tourism sector remains scant. However, Bitner (1992) in his study on the impact of physical surroundings on consumers and employees has a brief reference to employees, but with a focus on consumers [23]. For the conceptual model, see Figure 2.

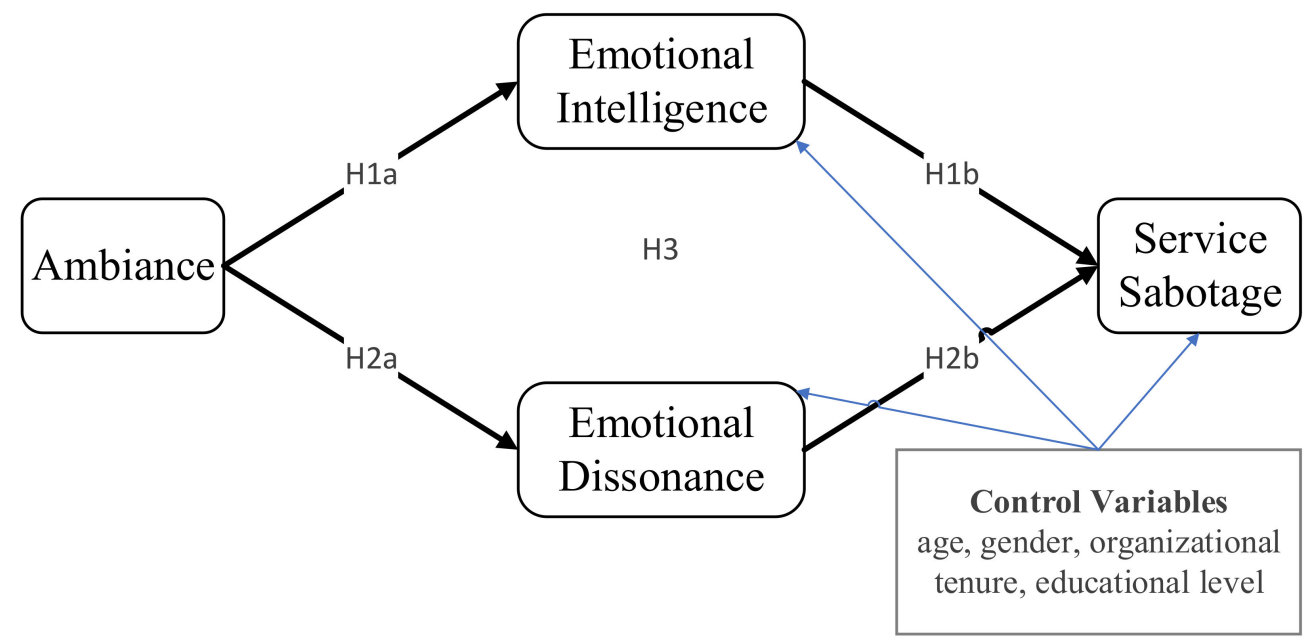

Figure 2. Conceptual model.

\section{Literature and Constructs}

\subsection{Ambient/Ambiance}

Ambient or the physical environment is referred to 'background conditions that exist below the level of our immediate awareness' (e.g., air quality, temperature, humidity, ventilation, noise, architecture, color, odor, texture, and functionality, etc.) [24] (p. 150). Bitner (1992) refer to ambient as 'servicescape', which is defined as 'the overall or total construct of environmental dimensions, rather than being a single component [23]. The components of servicescape have been classified into three dimensions: Ambient conditions; space/function and sign; and symbols and artifacts' (as cited in Durna et al., 2015 [25] (pp. 1730-1731).

Even though there is a degree of overlap between ambient, ambiance, and servicescape, ambiance is referred to as feelings of pleasure, stimulation, and immersion when one is embedded in a physical environment/ambient $[19,23]$. Thus, 'servicescape can therefore be used as a tool for making experience evaluations of customers [employees] easier' (as cited in Durna et al., 2015 [25] (p. 1729). Lee (2011) furthermore emphasizes the necessity for the hotel industry to use different components of servicescape, such as ambiance, service, convenience, decor, and design, to be competitive within the market [26]. Bitner (1992) further noted how ambient conditions including background characteristics of the working environment (e.g., in a hotel), and can be affected by temperature, lighting, noise, music, scent, spatial layout, and equipment with their functionality having the ability to facilitate the performance [23].

Numerous studies have focused on employees as one aspect of the service provision environment (e.g., restaurant, hotel, supermarket, department store, etc.) in relation to employee presentation and interaction with customers [29-32]. Some authors have also raised the issue of 'emotion' mildly, mainly in relation to patron and customer behavioral response to ambiance characteristics [33-35]. However, employees' emotional intelligence and emotional dissonance that are affected by ambiance characteristics with the consequential behavior of service sabotage remaining to be unexplored. 


\subsection{Emotional Intelligence}

'Emotional intelligence is a type of social intelligence that involves the ability to monitor one's own and others' emotions, to discriminate among them, and to use the information to guide one's thinking and actions' [36] (p. 433). Lechner and Paul (2017) studied service employees' emotion authenticity as well as the variability of displayed emotion from customers' point of view [37]. They highlighted that 'display of positive emotions in service employee-customer interactions is key to satisfactory service delivery in many service industries' [37] (p. 195). Cheung and Tang confirmed the quality of work-life and workplace as an important mediator in affecting emotion [38]. Grandey (2000) and Gross (1998) realized that employees need to experience pleasant internal feelings as psychological mechanisms in the workplace, e.g., smile-congruence to emotional intelligence, something that organizations desire as an emotional expression in the workplace [33,39]. However, organizations may have overlooked the effect of workplace ambiance, which may have different emotional consequences (i.e., emotional dissonance) and eventually actionize service sabotage [3]. However, the effect of ambiance characteristics on the variability of service employees has been poorly understood.

Mayer et al.'s (2011) classification of emotional intelligence established a reasonable argument for the role of emotional intelligence as the behavioral state of a person's action in the context of environmental psychology $[19,40,41]$ (see also Table 1). For instance, in Assimilating Emotion in Thought, Mayer et al. (2011) claimed that 'using emotions to prioritize thinking in productive ways' can be by ambient or workplace and associated characteristics of that space (e.g., regarding the service employees in this case) [34] (p. 532). Bitner (1992) categorizes service environment (where service employees are embedded) 'into ambient conditions, space or function, and sign/symbols/artifacts as the three main dimensions [23]. Ambient conditions include temperature, lighting, noise, music, and scent are those that have an effect on the five sense organs, while space refers to the arrangement of facilities in the service environment in a particular order for the attainment of a particular function' (as cited in Jani and Han, 2015 [12] (p. 49).

Table 1. Classification of emotional intelligence.

\begin{tabular}{|c|c|c|c|}
\hline $\begin{array}{l}\text { Perception and Expression } \\
\text { of Emotion }\end{array}$ & $\begin{array}{c}\text { Assimilating Emotion in } \\
\text { Thought }\end{array}$ & $\begin{array}{l}\text { Understanding and } \\
\text { Analyzing Emotion }\end{array}$ & $\begin{array}{c}\text { Reflective Regulation of } \\
\text { Emotion }\end{array}$ \\
\hline $\begin{array}{l}\text { Identifying and expressing } \\
\text { emotions in one's physical } \\
\text { states, feelings, and thoughts. } \\
\text { Identifying and expressing } \\
\text { emotions in other people, } \\
\text { artwork, language, etc. }\end{array}$ & $\begin{array}{l}\text { Using emotions to prioritize } \\
\text { thinking in productive ways. } \\
\text { Generating emotions as aids } \\
\text { to judgment and memory. }\end{array}$ & $\begin{array}{l}\text { Labeling emotions, including } \\
\text { complex emotions, and } \\
\text { recognizing simultaneous } \\
\text { feelings. } \\
\text { Understanding relationships } \\
\text { associated with shifts of } \\
\text { emotion. }\end{array}$ & $\begin{array}{l}\text { Staying open to feeling. } \\
\text { Being able to reflectively } \\
\text { monitor and regulate } \\
\text { emotions to promote } \\
\text { emotional and intellectual } \\
\text { growth. }\end{array}$ \\
\hline
\end{tabular}

Source: Adopted from Mayer et al. (1997) [42] (p. 532).

\subsection{Emotional Dissonance}

In contrast to emotional intelligence, emotional dissonance carries a negative connotation with disturbing consequences in the context of environmental psychology. Emotional dissonance is 'defined as the extent to which felt emotion differs from the emotion that should be expressed as required by display rules' [35] (p. 64). However, emotional dissonance can be the cause of behavior not necessarily in following the rules that are required from employees. For example, a service employee in a hotel may develop emotional behavior/dissonance due to ambiance characteristics and not act in a friendly manner with tourists during a service encounter. This is because emotional dissonance (as a mediator) [43] is a stressor that debilitates the effective performance of the task and as such can become a threat to organizational reputation [44]. Zapf et al., (1999) argued that emotional dissonance is a stressor that impairs the effective fulfillment of the task and as such can become a threat to employee well-being [45]. Mehrabian and Russell (1974) in their 
discourse of emotion 'operationalized pleasure purely in terms of positive or negative feelings [19]. However, two decades later, Mehrabian (1996) 'operationalized pleasure in a rather different way and used connotations such as excitement, relaxation, love, and tranquility versus cruelty, humiliation, disinterest and boredom' (as cited in Bakker et al., 2014 [22] (p. 410).

In the context of Mehrabian's (1996) operationalization of pleasure and displeasure (Figure 1 ) as well as the S-O-R model $[23,46]$, the response behavior of service employees can engender emotional dissonance (i.e., cruelty, humiliation, disinterest, and boredom), and consequently service sabotage. Moreover, the path towards such a response has a link to the servicescape or ambient and associated characteristics. Emotional dissonance, in which service sabotage is its manifestation, is indirectly explained by the theory of Conservation of Resources (COR) [3,40].

Based on the COR, it is plausible for a situation (e.g., characteristics of ambientservicescape) to be emotionally charged (emotional dissonance or physical depletion), which can undermine employee work ethic and value (authenticity). Lee and Ok (2014) elaborated that such employees:

‘May feel emotional and physical depletion, a lack of energy and extreme tiredness, even feelings too drained of emotional resources to cope with continuing demands. This may lead to poor self-esteem and self-efficacy, and they begin to feel less competent and less successful, reducing their sense of personal accomplishment, causing them to evaluate themselves negatively in productivity' [3] (p. 178).

The assumption is that servicescape or ambient can affect the expression of emotion in ones' physical states, feelings, and thoughts (Table 1) [45] with negative implications including service sabotage. Similarly, research on emotion work has identified several person- and work-related antecedents of emotional dissonance (or surface acting). With respect to service sabotage, 'surface acting implies a state of emotional dissonance' [35] (p. 64). It is plausible to argue that emotional dissonance as a mediator for service sabotage in the context of situational setting (ambient), conceptualized 'as a clash between 'real' and 'false' emotion predicated on an authentic self that is transmuted in organizational settings' [41] (p. 1530). This is in line with Grandey's (2000) assertion that 'the job environment or a particular work event may induce an emotion response in the employee (e.g., anger, sadness, anxiety), and behaviors may follow that would be inappropriate for the encounter (e.g., verbal attack, crying, complaining) [33] (p. 99).

\subsection{Service Sabotage}

Dysfunctional tendencies of employees are not limited to the service sector of tourism; it has been witnessed in the past and in various other sectors. In the studies of the hospitality and tourism sectors, Lee and Ok (2014) cited that 'more than $85 \%$ of customer-contact employees reported having engaged in some forms of service sabotage, and $100 \%$ of the service employees in one study reported that service sabotage occurs every day in their workplace' [3] (p. 178). Along with Mehrabian-Russell's theory of S-O-R, COR [40] also offers an alternative explanation for the emotional response with implications for service sabotage as an individual appraisal or specific environmental approaches to stress [47]. The recent revision of COR 'unfolds its development, focusing on the individual within the context of work [ambient setting] as one of the most significant arenas' [47] (p. 170). One should bear in mind that 'ambient' and its components contain dimensions of function, impact, and interaction. In a hotel setting, this has implications for users/customers and service encounters. Durna et al. (2015) found that 'ambient conditions are composed of temperature, quality of air, voice, music, smell, and etc., whereas space/function is composed of design, decoration, and business equipment [25] (p. 1731). Signs, symbols, and artifacts are used in a physical environment with the aim of transmitting what is necessary for users or for enabling communication'. 
Service sabotage as a behavioral/emotional dissonance response to the effect of ambient/servicescape is contextualized by Trigg (2006) [48]. He argued 'that context does have an influence on the distinction between disinterestedness and interestedness and that the hotel lobby is an excellent illustration of a spatial context that facilities disinterested delight for the reason that it is largely impersonal, indifferent, and so universal' [48] (p. 418).

We assume that the ambiance elements of servicescape not only is of strategic importance pertaining to the image of high-quality service in the hotel sector, they are also evoking emotional responses from employees [25]. Bitner (1992) applied the S-O-R paradigm for and employed the term servicescape in reference to the atmospheric description in service settings to understand the impacts of physical surroundings on employees and customers [23]. In concordance with Bitner (1992), Turley and Milliman (2000) also discussed the organism and emotional responses of both customers and employees with an implication for customers in terms of the affective image of servicescape, and for employee behavior in terms of service sabotage [23,32].

\subsection{Proposing Hypothesis}

Based on the aforementioned literature and constructs, the following hypothesis are proposed:

Hypothesis 1a (H1a). Ambiance/servicescape positively evokes emotional intelligence.

Hypothesis 2a (H2a). Ambiance/servicescape negatively evokes emotional dissonance.

Hypothesis $1 \mathbf{b}(\mathbf{H 1 b})$. Emotional intelligence negatively evokes service sabotage.

Hypothesis $\mathbf{2 b} \mathbf{( H 2 b ) . ~ E m o t i o n a l ~ d i s s o n a n c e ~ p o s i t i v e l y ~ e v o k e s ~ s e r v i c e ~ s a b o t a g e . ~}$

In sum, by integrating all the hypotheses we proposed a parallel mediation of EI and ED between the relationship of ambiance and SS:

Hypothesis 3 (H3). Emotional intelligence and emotional dissonance mediate the relationship between ambiance/servicescape and service sabotage in a parallel manner.

\section{Methods}

\subsection{Sampling and Survey Procedures}

The respondents of this research were service employees who are continuously in contact with customers. The target population was employed by five- and four-star hotels in north Cyprus. A total of 6 five-star and 3 four-star hotels were selected from 4 locations, which are classified as a tourist hotspot. For the location of the hotels, see Figure 3. Prior to the distribution of the questionnaires, the general managers of the hotels were contacted and the purpose of the study explained. After receiving their consent, questionnaires were delivered. In the meantime, we explained and requested that the questionnaires be completed on a timely basis, meaning that respondents should have enough time to focus rather than to rush through the process [49]. Employees who were not in regular contact with customers were excluded.

Overall, 400 survey questionnaires were distributed, of which 378 valid questionnaires were returned (90.0\% response rate). The drop-off/pick-up method for survey research was used whereby questionnaires were delivered by hand to the managers in each hotel to be distributed. A pretesting/pilot study was adhered to in order to identify items that respondents might have difficulty understanding or interpreting in a way that was different to what the researcher intended [50].

For the purpose of this study, a judgmental/purposive sampling was applied, which is a highly-used method in the field of organization studies [51]. Data collection was accom- 
plished during the summer of 2019 prior to the pandemic outbreak. For the demographic characteristics of the respondents, see Table 2.

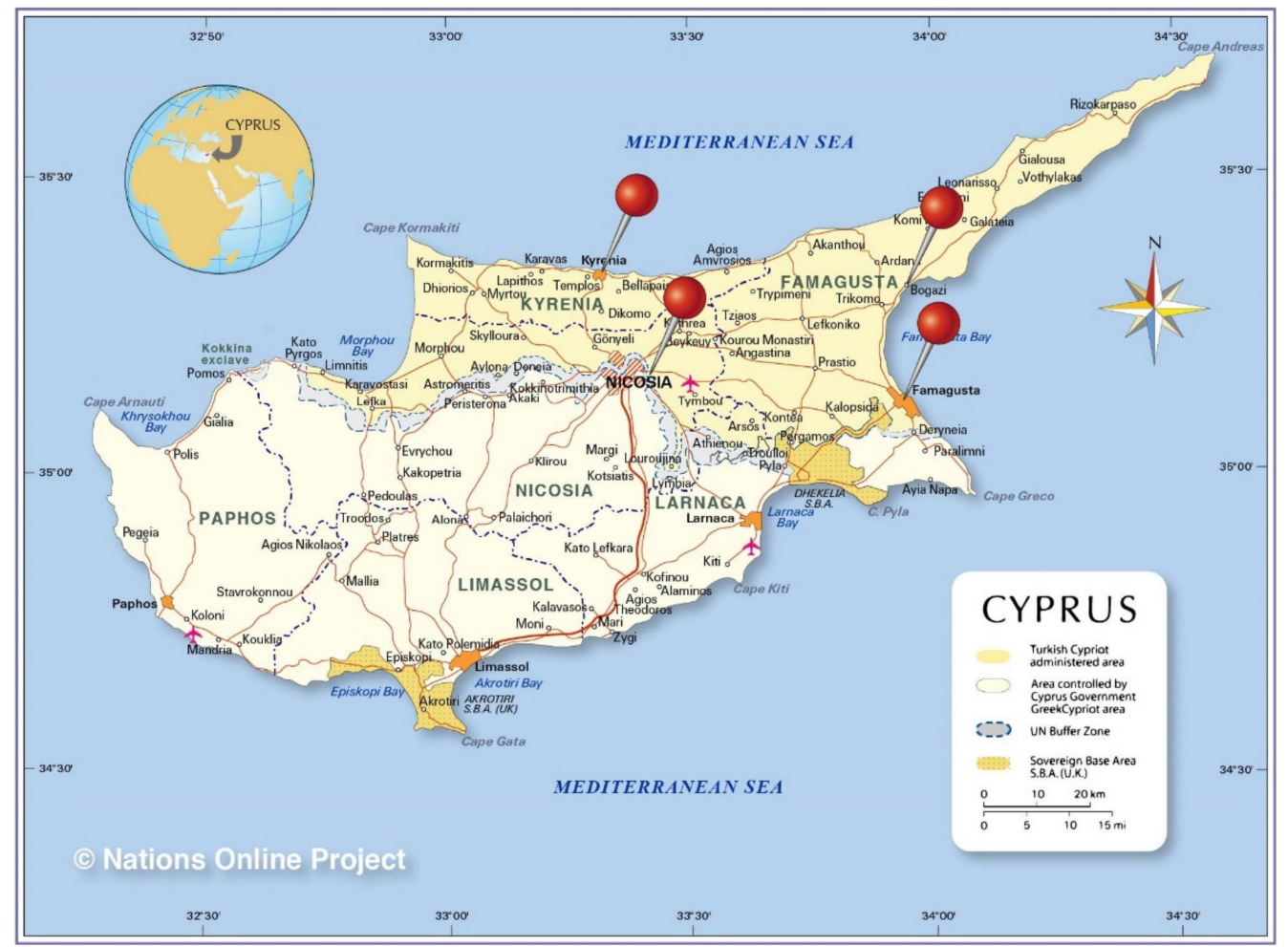

Figure 3. The location of surveyed hotels.

Table 2. Respondent's Profile.

\begin{tabular}{cccc}
\hline Items & & Frequency & \% \\
\hline Age & 20 and below & 26 & 6.9 \\
& $21-30$ & 210 & 55.6 \\
& $31-40$ & 112 & 29.6 \\
& $41-50$ & 28 & 7.4 \\
Gender & $51-60$ & 1 & 0.3 \\
& 61 and above & 1 & 0.3 \\
Nationality & Female & 142 & 37.6 \\
& Male & 236 & 62.4 \\
Marital status & Cypriot & 121 & 32 \\
& Turkish & 241 & 63.8 \\
Educational Level & Other & 16 & 4.2 \\
& Married & 140 & 37 \\
& Single & 238 & 63 \\
& Primary school & 14 & 3.7 \\
& Secondary school & 37 & 9.8 \\
& High school & 122 & 32.3 \\
& University & 194 & 51.3 \\
Organizational Tenure & Master & 11 & 2.9 \\
& Less than one year & 101 & 26.7 \\
& 1-5 years & 214 & 56.6 \\
& 6-10 years & 53 & 14 \\
& 11 years and above & 10 & 2.6 \\
& Less than one year & 50 & 13.2
\end{tabular}




\subsection{Measurement Instrument}

All valid measurement instruments were chosen from previous studies relevant to ambiance and emotional behavior (e.g., [14,32,47,52]). Each item is scored on a 1-5 Likert scale ranged from (one $=$ strongly disagree) to $($ five $=$ strongly agree). The reliability test in the study demonstrated that these measurements provided adequate levels of internal consistency as alpha values were above the cut-off point of 0.70 [53].

Turley and Milliman (2000) found that there have been ample studies and evidence about the impacts of the service environment on consumer behavior, especially in restaurants and hotels within the hospitality industry $[39,52,54]$. However, there has been limited research done from the perspective of employee behavior. Nevertheless, most of the studies on this topic have been on marketing and customer behavior with limited studies on service employees [55]. In this study, we adopted 6 items for measuring hotel ambiance from previous research [14]. The ambiance score of each hotel was rated by service employees. All of these statements were measured by a five-point Likert scale. The Cronbach's alpha for the ambiance was 0.904 . The results of coefficient alpha scale items are listed in Table 3.

The Wong and Law Emotional Intelligence Scale (WLEIS) [56] (i.e., 16-items) were applied, which are conceptualized by Mayer and Salovey (1997) and include four components of EI (i.e., self-emotion appraisal, other-emotion appraisal, use of emotion, and regulation of emotion) [45]. The EI was rated by service employees. The coefficient alpha for the emotional intelligence scale in this study was 0.929 . The emotional dissonance was rated by service employees, using 9 items drawn from Chu and Murrmann's (2006) known as the Hospitality Emotional Labor Scale (HELS) [57].

The coefficient alpha for emotional dissonance in this study was 0.819. The HELS evaluates the emotional labor of hospitality employee performance during the service encounter. The example of sample items are: "The emotions I show to customers match what I truly feel" and "I fake a good mood when interacting with customers".

For Service Sabotage (SS) construct, nine items were used derived from the work of Harris and Ogbonna (2006) [58]. The Service Sabotage scale is rated by customer contact with employees. In this study, service employees were asked to indicate the extent to which they agreed with each statement about their service sabotage related behaviors. The Cronbach's alpha for service sabotage was 0.917 .

\subsection{Control Variables}

To rule out alternative explanations for the findings, previous studies indicated that demographic features such as age, gender, organizational tenure, and organizational experience are linked to ED, EI, and SS [52,59,60]. Therefore, demographic characteristics were used as control variables in all analyses to guarantee that the relationships among variables are not confounded.

\subsection{Data Analysis and Results}

Prior to the estimations, case and variable screening were checked and no missing data were observed. The normality of the data set was checked and the skewness and kurtosis of the variables were within recommended ranges of \pm 3.3 as the upper threshold for normality indicating the relatively normal distribution of the data [61].

In order to confirm the convergent validity, a Confirmatory Factor Analysis (CFA) was performed via AMOS 24.0 [54], which measures various fit statistics for the assessment of the measurement model in CFA. Cronbach's alpha coefficient, composite reliability, and the Heterotrait-Monotrait Ratio of Correlations (HTMT) were measured to confirm the reliability of the variables. HTMT as a new criterion for assessing the discriminant validity is used instead of the average variance extracted which is measured by the suggestion of Voorhees et al. (2016) [62]. In order to analyze the parallel mediation effect, the macro PROCESS model 4, V.3.5 for SPSS V.25 was employed using a bootstrapped 5000 sample size via the $95 \%$ confidence interval [63]. 
Table 3. Scale items and reliability results.

\begin{tabular}{|c|c|c|c|c|}
\hline Items & Loading & $t$-Value & $\alpha$ & CR \\
\hline Ambiance $(\mathrm{Amb})$ & & & 0.904 & 0.906 \\
\hline The air quality in this hotel is appropriate (general construct). & 0.955 & $19.894^{* * *}$ & & \\
\hline The temperature in this hotel is comfortable. & $1.000 *$ & $\mathrm{n} / \mathrm{a}$ & & \\
\hline It is not too dry/humid in this hotel (specific construct). & 0.865 & $17.798^{* * *}$ & & \\
\hline The odor in this hotel is pleasant (pleasant scent). & 0.909 & $19.259 * * *$ & & \\
\hline The background music played overhead makes the hotel a more enjoyable place. & 0.892 & $15.395^{* * *}$ & & \\
\hline The sound level in this hotel is not too loud (noise). & 0.752 & $14.448 * * *$ & & \\
\hline Emotional Intelligence (EI) & & & 0.929 & 0.922 \\
\hline I have a good sense of why I have certain feelings most of the time. & - & - & & \\
\hline I have good understanding of my own emotions. & 0.867 & $13.175^{* * *}$ & & \\
\hline I really understand what I feel. & 0.928 & $14.116^{* * *}$ & & \\
\hline I always know whether I am happy. & 0.937 & $15.034^{* * *}$ & & \\
\hline I always know my friends' emotions from their behavior. & 0.917 & $17.718^{* * *}$ & & \\
\hline I am a good observer of others' emotions. & $1.000 *$ & $\mathrm{n} / \mathrm{a}$ & & \\
\hline I am sensitive to the feelings and emotions of others. & 0.919 & $19.263^{* * *}$ & & \\
\hline I have good understanding of the emotions of people around me. & 0.975 & $15.826^{* * *}$ & & \\
\hline I always set goals for myself and then try my best to achieve them. & 0.882 & $14.365^{* * *}$ & & \\
\hline I always tell myself I am a competent person. & 0.795 & $10.727^{* * *}$ & & \\
\hline I am a self-motivated person. & 0.835 & $11.611^{* * *}$ & & \\
\hline I would always encourage myself to try my best. & 0.854 & $12.166^{* * *}$ & & \\
\hline I am able to control my temper and handle difficulties rationally. & 0.773 & $10.872 * * *$ & & \\
\hline I am quite capable of controlling my own emotions. & 0.835 & $12.335 * * *$ & & \\
\hline I can always calm down quickly when I am very angry. & 0.826 & $10.631^{* * *}$ & & \\
\hline I have good control of my own emotions. & 0.837 & $11.651 * * *$ & & \\
\hline Emotional Dissonance (ED) & & & 0.819 & 0.790 \\
\hline I fake a good mood when interacting with customers. & - & - & & \\
\hline I fake the emotions I show when dealing with customers. & 0.541 & $8.627^{* * *}$ & & \\
\hline I put on a mask in order to express the right emotions for my job. & 0.633 & $10.331^{* * *}$ & & \\
\hline The emotions I show to customers match what I truly feel. & - & - & & \\
\hline I behave in a way that differs from how I really feel. & 0.604 & $10.073^{* * *}$ & & \\
\hline I put on an act in order to deal with customers in an appropriate way. & - & - & & \\
\hline My interactions with customers are very robotic. & 0.888 & $14.09 * * *$ & & \\
\hline I display emotions that I am not actually feeling. & $1.000 *$ & $\mathrm{n} / \mathrm{a}$ & & \\
\hline I have to cover up my true feelings when dealing with customers. & 0.511 & $8.759 * * *$ & & \\
\hline I actually feel the emotions that I need to show to do my job well. & - & - & & \\
\hline I show the same feelings to customers that I truly feel myself. & - & - & & \\
\hline Service Sabotage (SS) & & & 0.917 & 0.917 \\
\hline People here take revenge on rude customers. & 0.941 & $21.803 * * *$ & & \\
\hline People here hurry customers when they want to. & 0.888 & $16.758 * * *$ & & \\
\hline It is common practice in this industry to "get back" at customers. & $1.000 *$ & $\mathrm{n} / \mathrm{a}$ & & \\
\hline People here ignore company service rules to make things easier for themselves. & 0.875 & $17.11^{* * *}$ & & \\
\hline Sometimes, people here "get at customers" to make the rest of us laugh. & 0.955 & $23.505 * * *$ & & \\
\hline People here never show off in front of customers. & - & - & & \\
\hline Sometimes, when customers are not looking, people here deliberately mess things up. & 0.870 & $17.94^{* * *}$ & & \\
\hline At this outlet, customers have never deliberately mistreated. & - & - & & \\
\hline People here slow down service when they want to. & 0.853 & $15.215^{* * *}$ & & \\
\hline
\end{tabular}

Note:-dropped during CFA; * Fixed parameter; ${ }^{* * *} p<0.001$; Kaiser-Meyer-Olkin (KMO): 0.893 and Bartlett's test of Sphericity: 9747.187 [703] was significant at $p<0.001$; Model fit statistics; $x^{2}[499]=1334.455, x^{2} / d f=2.674 ;$ IFI $=0.904 ;$ CFI $=0.903 ;$ RMSEA [90 per cent CI] = 0.067 [0.062, 0.071]; SRMR = 0.067; CR = Composite Reliability; IFI = Incremental Fit Index; CFI = Comparative Fit Index; RMSEA = Root Mean Square Error of Approximation; SRMR = Standardized Root Mean Square Residual; and CI = Confidence Interval.

The exploratory factor analysis was performed to assess how much variance in the study's variables can be explained through a single factor. If a single factor emerges or one general factor accounts for most of the covariance in the independent and dependent variables, a significant Common Method Variance (CMV) is present [64]. All four variables were entered into the exploratory factor analysis, using the extraction method of maximum likelihood through the rotation method of Promax with Kaiser normalization, in order to determine the number of factors needed to consider for variance in the variables. As a 
result of factor analysis, it is revealed that all distinct factors with eigenvalues are found greater than 1.0, and are therefore not a single factor. The factors together accounted for $51.53 \%$ of the total variance. Consequently, results displayed that the potential of the common method bias is minimized.

\subsection{Hypothesis Test}

Table 4 exhibits the results for means, standard deviations, and correlations of the study and control variables. Gender, age, organizational tenure, and organizational experience, as control variables, are not significantly correlated with dependent variables. The ambiance is positively and significantly related to Emotional Intelligence $(r=0.543$, $p<0.001$ ), which means H1a is supported. Emotional Intelligence negatively and significantly related to service sabotage $(r=-0.280, p<0.001)$, which shows H1b is supported. The ambiance was found as positively and significantly related to emotional dissonance $(r=0.117, p<0.1)$. H2a proposed that ambiance is negatively related to ED and results showed that $\mathrm{H} 2 \mathrm{a}$ is partially supported. ED is related to Service Sabotage positively $(r=0.345, p<0.001)$. Therefore, $\mathrm{H} 2 \mathrm{~b}$ is also supported.

Table 4. Correlations, descriptive statistics, and HTMT ratios.

\begin{tabular}{|c|c|c|c|c|c|c|c|c|c|}
\hline Construct & (1) & (2) & (3) & (4) & (5) & (6) & (7) & (8) & SD \\
\hline (1) Ambiance & 4.113 & 0.542 & 0.189 & 0.298 & & & & & 1.062 \\
\hline (2) Emotional Intelligence & $0.543^{* * *}$ & 4.001 & 0.215 & 0.264 & & & & & 0.968 \\
\hline (3) Emotional Dissonance & $0.197^{* *}$ & $0.117^{+}$ & 3.282 & 0.293 & & & & & 1.353 \\
\hline (4) Service Sabotage & $-0.305^{* * *}$ & $-0.280 * * *$ & $0.345^{* * *}$ & 2.014 & & & & & 1.239 \\
\hline (5) Age & 0.027 & 0.024 & $-0.134^{* *}$ & -0.080 & 2.394 & & & & 0.757 \\
\hline (6) Gender & 0.047 & 0.041 & -0.060 & -0.009 & 0.050 & 1.624 & & & 0.485 \\
\hline (7) Organizational Tenure & 0.045 & 0.072 & -0.035 & 0.000 & $0.466^{* *}$ & 0.057 & 1.926 & & 0.714 \\
\hline $\begin{array}{l}\text { (8) Organizational } \\
\text { Experience }\end{array}$ & -0.016 & 0.077 & $-0.102 *$ & -0.049 & $0.425^{* *}$ & $0.118 *$ & $0.519 * *$ & 2.294 & 0.818 \\
\hline
\end{tabular}

Note: Diagonal elements in italic are the means; upper diagonal elements in bold are HTMT ratios; lower diagonal elements are correlations; ${ }^{+} p<0.100 ;{ }^{*} p<0.050 ;{ }^{* *} p<0.010 ;{ }^{* * *} p<0.001$ (2-tailed); SD: Standard Deviation, HTMT = Heterotrait-Monotrait Ratio of Correlations.

Table 5 summarizes the result of unstandardized coefficients for all variables. The results demonstrated that all the relations in these analyses were significant and accordingly the parallel mediation conditions were supported. Specifically, hypotheses $1 \mathrm{a}$ and $1 \mathrm{~b}$ proposed that ambiance via EI is associated with service sabotage. The significance relation of ambiance with EI $(B=0.455, p<0.001)$ and EI with service sabotage $(B=-0.260$, $p<0.050)$ proposed that EI mediate this relation significantly. Based on this hypothesis, $1 \mathrm{a}$ and $1 b$ were supported. Hypothesis $2 a$ and $2 b$ predict the relation between ambiance and service sabotage is mediate by EI. The significance relation of ambiance with $E D(B=0.283$, $p<0.001)$ and ED with service sabotage $(B=-0.426, p<0.001)$ proposed that ED mediate this relation significantly. Although there is evidence of a significant mediator role in hypothesis $2 \mathrm{a}$, it was demonstrated that ambiance is negatively associated with ED while the result of Table 4 proposes that ambiance is positively related to ED. Thus, hypothesis $2 a$ is partially supported. All control variables were insignificant except age in the relationship between ambiance and $\mathrm{ED}(\mathrm{B}=-0.206, p<0.050)$.

The results indicate that beyond control variables (age, gender, tenure, and experience), the ambiance is significant as an independent of service sabotage $(B=-0.381, p<0.001)$. The significant mediating effects of both EI $(B=-0.119, \mathrm{CI}:-0.201,-0.044)$ and ED (B $=0.121$, CI: $0.066,0.181)$ reveals that the parallel mediation of EI and ED are significantly supported. Thus, hypothesis 3 is supported.

The total effect that is the summation of all indirect effects and direct effect is estimated hypothetically through regressing ambiance on SS alone. The total effect was statistically significant $(\mathrm{B}=-0.379, p<0.001)$. Therefore, employees reported lower service sabotage even though the ambiances indirect effect through both emotional intelligence and emo- 
tional dissonance was taken into account. Again, this indicates the parallel mediation role of the mediators in this relationship. Although we did not hypothesize the direct effect of ambiance on SS, the process model always suggested a null hypothesis of direct effect to be equal to zero. According to the main findings, the model is revised as shown in Figure 4.

Table 5. Model test results.

\begin{tabular}{|c|c|c|c|c|c|c|}
\hline & B & SE & $p$-Value & LLCI & ULCI & $\mathbf{R}^{2}$ \\
\hline $\mathrm{Amb} \rightarrow \mathrm{EI}$ & 0.455 & 0.055 & $0.000 * * *$ & 0.347 & 0.546 & $0.358^{* * *}$ \\
\hline \multicolumn{7}{|l|}{ Control variables } \\
\hline Age & -0.036 & 0.051 & 0.481 & -0.136 & 0.064 & \\
\hline Gender & 0.004 & 0.061 & 0.954 & -0.115 & 0.123 & \\
\hline Org_Tenu & 0.014 & 0.050 & 0.773 & -0.083 & 0.112 & \\
\hline Org_Expe & 0.080 & 0.041 & 0.052 & -0.001 & 0.160 & \\
\hline $\mathrm{Amb} \rightarrow \mathrm{ED}$ & 0.283 & 0.060 & $0.000^{* * *}$ & 0.164 & 0.402 & $0.074^{* * *}$ \\
\hline \multicolumn{7}{|l|}{ Control variables } \\
\hline Age & -0.206 & 0.084 & $0.015^{*}$ & -0.372 & -0.039 & \\
\hline Gender & -0.139 & 0.118 & 0.239 & -0.372 & 0.093 & \\
\hline Org_Tenu & 0.087 & 0.100 & 0.383 & -0.109 & 0.283 & \\
\hline Org_Expe & -0.086 & 0.088 & 0.325 & -0.258 & 0.086 & \\
\hline $\mathrm{Amb} \rightarrow \mathrm{SS}$ (Direct Effect) & -0.381 & 0.067 & $0.000^{* * *}$ & -0.514 & -0.248 & $0.349^{* * *}$ \\
\hline $\mathrm{EI} \rightarrow \mathrm{SS}$ & -0.260 & 0.094 & $0.006^{* *}$ & -0.446 & -0.075 & \\
\hline $\mathrm{ED} \rightarrow \mathrm{SS}$ & 0.426 & 0.044 & $0.000^{* * *}$ & 0.340 & 0.512 & \\
\hline \multicolumn{7}{|l|}{ Control variables } \\
\hline Age & -0.036 & 0.066 & 0.589 & -0.165 & 0.094 & \\
\hline Gender & 0.089 & 0.091 & 0.325 & -0.089 & 0.267 & \\
\hline Org_Tenu & 0.092 & 0.079 & 0.244 & -0.063 & 0.247 & \\
\hline Org_Expe & -0.025 & 0.068 & 0.717 & -0.158 & 0.109 & \\
\hline $\mathrm{Amb} \rightarrow \mathrm{EI} \rightarrow \mathrm{SS}$ & -0.119 & 0.040 & - & -0.201 & -0.044 & - \\
\hline $\mathrm{Amb} \rightarrow \mathrm{ED} \rightarrow \mathrm{SS}$ & 0.121 & 0.029 & - & 0.066 & 0.181 & - \\
\hline Total effect & -0.379 & 0.064 & $0.000^{* * *}$ & -0.505 & -0.253 & $0.119 * * *$ \\
\hline \multicolumn{7}{|l|}{ Control variables } \\
\hline Age & -0.114 & 0.074 & 0.126 & -0.260 & 0.032 & \\
\hline Gender & 0.029 & 0.108 & 0.790 & -0.184 & 0.242 & \\
\hline Org_Tenu & 0.125 & 0.091 & 0.170 & -0.054 & 0.305 & \\
\hline Org_Expe & -0.082 & 0.071 & 0.247 & -0.221 & 0.057 & \\
\hline
\end{tabular}

Note: ${ }^{*} p<0.050 ;{ }^{* *} p<0.010,{ }^{* * *} p<0.001 ; \mathrm{B}=$ Unstandardized coefficients; $\mathrm{SE}=$ Standard Error; Number of bootstrap samples: 5000 (95 confidence intervals); Org_Tenu = Organizational Tenure; Org_Expe = Organizational Experience.

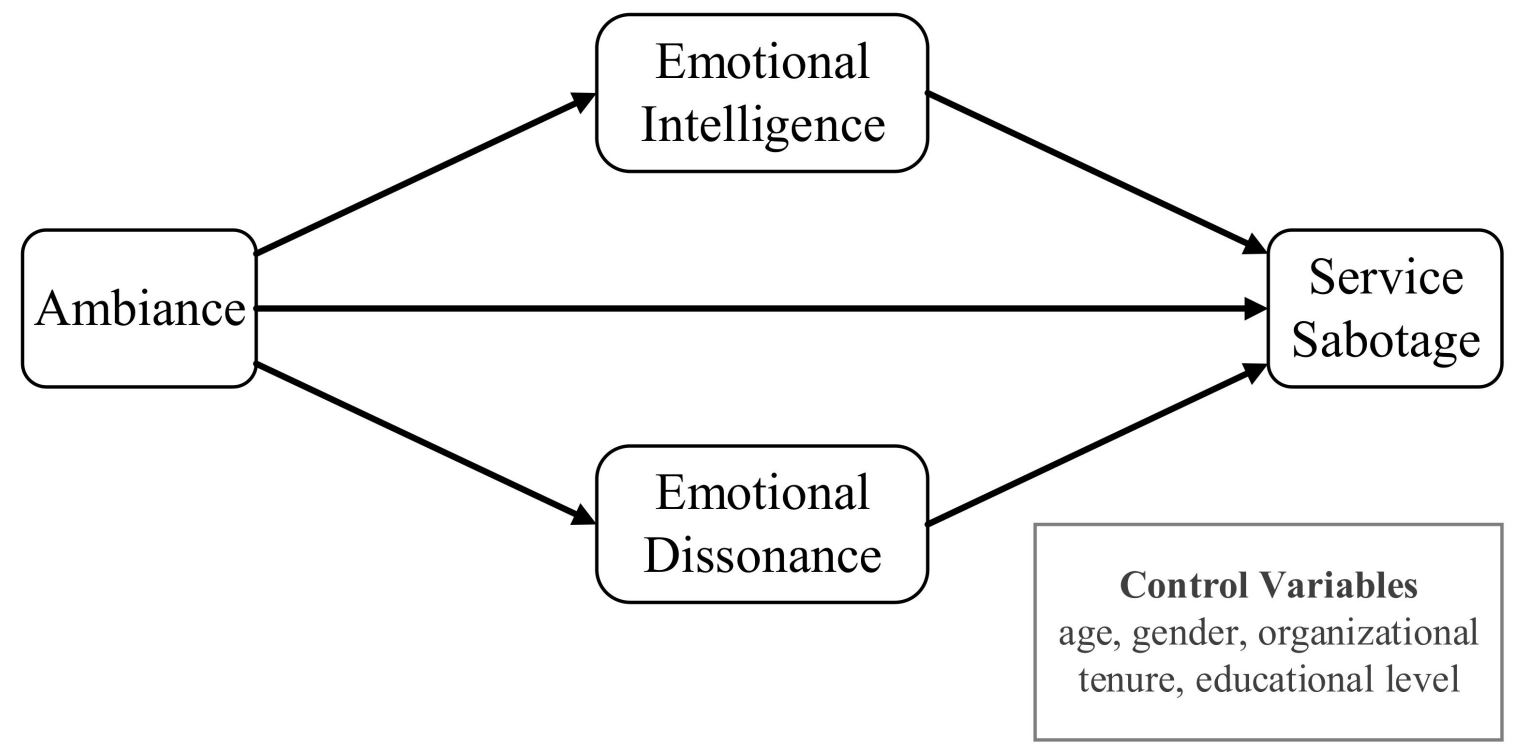

Figure 4. Revised model. 


\section{Discussion and Conclusions}

The current study tries to clarify how the environmental stimuli and emotional labor of service employees can affect service sabotage, and how EI and ED can mediate this relation. According to the $\mathrm{M}-\mathrm{R}$ model and the S-O-R framework, we hypothesized that: (a) EI and ED are important sources of SS, (b) ED mediates the relation of ambiance and Service Sabotage negatively, and (c) Emotional Intelligence also mediates the relation of Ambiance and Service Sabotage but positively. To examine the hypotheses, we analyzed the effect of ambiance on ED and EI, the effect of these two on SS, and at the end pointed out the effect of ambiance on SS with two mediators' effect.

The result of our tests showed that ambiance positively affects the ED and EI, which means that the environmental stimuli easily influence the psychometrical and personal factors of hospitality employees during their organizational experience. These findings validate the claims of numerous scholars (e.g., [11,65-67]) who are in accord with Schreuder et al.'s (2016) assertion that:

'Environmental characteristics such as luminosity of light sources, the nature and level of ambient noise and acoustics, the presence of specific odors, color hues and shades, and materials and atmospheric factors such as temperature and humidity, all generate sensory input, and combined contribute to specific reactions in the observer [e.g., service employees] (as cited in Schreuder et al., 2016 [11] (p. 1).

As predicted, ED is positively related to service sabotage, while EI reduces service sabotage. This is also in concordance with Lee and Ok's (2014) study who applied COR theory to the topic of SS and hospitality industry employees' interaction with tourists with implications for service quality [3]. The study has also revealed that a negative association between EI and service sabotage, as predicated on characteristics of servicescape, can affect employees as a way to realize and regulate their own, and others' emotions with less engagement in SS. It was also determined that staff with high EI are more engaged in an effortful process through which employees change their internal feelings to align with organizational expectations, producing more natural and genuine emotional displays (deep acting), unlike ED, which is more likely to involve faking the required emotions (surface acting) [68]. The mediating role of EI and ED in service sabotage emanating from servicescape is in line with Mikolajczak et al. (2007) in which 'trait EI was found to be associated with less mood deterioration and less emotional reactivity (emotional intensity, action tendencies, and bodily sensations) following a laboratory stressor' [reduced tendency towards service sabotage] [69] (p. 107). The result of the study has revealed that hotel service employees with high EI can save emotional resources to use for appropriate emotional labor, reducing negative environmental stimuli, and thus, feel frustration as much as others which may otherwise lead to service sabotage. This also signifies the significance of servicescape/ambiance characteristics on emotional labor outcome. The result also validates that the workplace (servicescape) should be perceived as a rational environment, where emotions/behaviors can be affected by its attributes. As Grandy (2000) articulated, 'the situation acts as a cue to the individual, and the individual's emotional response tendency (physiological, behavioral, cognitive) provides information to that individual and the others in the social environment' (servicescape) [33] (p. 98).

Consequently, employees reported lower service sabotage through the parallel mediating effect of both emotional intelligence and emotional dissonance in the context of ambiance-service sabotage relationship. In this study, the results showed that the ambiance had a significant effect on reducing SS. Although we did not hypothesize this effect, the $\mathrm{M}-\mathrm{R}$ model, and S-O-R framework can perfectly explain this relationship. Meaning that ambiance as the independent source of emotions can mitigate employee SS behavior. This is another evidence for the important role of ambiance in reducing employee SS directly and indirectly through the mediators of EI and ED.

In relation to previous studies, this study is in line with Härtel et al. (2005), who studied organizational environment and emotion in the workplace and asserted that 
organizational environment (including ambiance characteristics) could induce positive emotions and reduce negative emotions [70]. Furthermore, this study complements the findings by So et al. (2020), who stated that one's emotional state is an important outcome of environmental stimuli (e.g., ambiance characteristics) in the context of the S-O-R model, which can also result in responses such as emotional behavior [15]. This study is also in agreement with findings of Lee and Ok (2014), who revealed that hospitality employees who experience emotional discrepancy are more likely to engage in SS [3]. They focused on the effect of burnout however, burnout is not the only stimuli to cause the depletion of psychological energy and emotional reaction. This study is also in concordance with Bitner's (1992) classical work who categorized 'service environment into ambient conditions, space or function, and signs/symbols/artifacts/as the three dimensions' (Jani and Han, 2015, p. 49) which influence positive or negative emotional responses [12,23]. This study is also in line with Liu and Perrewé (2005) who studied Counterproductive Work Behavior (CWB) in the context of psych-evolutionary theory of emotion, which indicated that 'a healthy work environment that allows for a wider range of emotional expression is very important both for the employee and the organization' [71]. Liu and Perrewé (2005) reiterated that employees can become dissatisfied because of a noisy servicescape and lack of resources which can demotivate and possibly result in CWB such as aggression, hostility, sabotage, and theft [71].

\section{Implications}

\subsection{Theoretical Implications}

This study, by using M-R and S-O-R models, explains the effect of service ambiance [12,72] components as a stimulus on emotional labor and SS. In this regard, it can be stated that examining servicescape and environmental stimulus has contributed to an understanding of the components (e.g., air quality, temperature, humidity, odor, music, color, shades, ventilation, noise, architecture, texture, functionality, etc.) of the working environment and their impact on emotional behavior with consequences for SS. In addition, it contributes to both practitioners and the literature by providing various suggestions to hotel managers and researchers. It also provides the theoretical reasoning and empirical testing of how ambiance affect emotional labor and how emotional labor expands to SS which theoretically affirms the utility of the extended M-R and S-O-R models with the inclusion of EI and ED personality as the mediators within the tourism and hospitality industry.

Previous studies have focused on personal traits and on-the-job attitude (e.g., $[12,43,73,74])$ and organizational injustice [75]. Others have focused on emotional responses (e.g., Jani and Han, 2013; Harris and Ogbonna, 2006), customer mistreatment of employees [76], Service Sabotage [35], and the influence of work status on organizational citizenship behavior [77]. However, there has not been any comprehensive study of servicescape/ambiance characteristics and service employee emotional labor (EI and ED) with consequences for SS. Investigating how workplace/ambiance characteristics affect negative workplace service employee emotional behaviors, such as SS, is somewhat lacking. This study explored EI and ED as two critical mediators in the model. This finding enriches the literature of SS and suggests the plausibility of relationships between workplace ambiance characteristics and employee emotional response to the amelioration of SS, which is considered deviant behavior.

\subsection{Practical Implications}

The practical implications of this study should be acknowledged and emphasized because of the frequent occurrence of SS in various organizations, especially in the tourism and hospitality sector [78]. Consequently, it disrupts and degrades the quality and value of service encounters, which is vital for a service sector organization's reputation and sustainability. In terms of practical implications, service sector managers (e.g., hotels and restaurants) should benefit from this empirical research that various factors including the 
workplace ambiance can play a role in inspiring service employees and their emotional response (EI and ED) either to curtail service sabotage or to entice it. The accommodation sector managers who wish to reduce and control SS behaviors should focus their efforts on the servicescape's impact by arranging meetings and listening to service employees' perceptions regarding the characteristics of the workplace. This way, they can understand service employees' feelings, attitudes, and suggestions. This approach by management can bear fruits in different ways. First, it can generate respect and loyalty between employees and the organization as employees will consider it a valuation of their labor (i.e., feeling valued) [79]. Managers should also pay attention that SS is not a uniform behavior, meaning that different service employees will apply different ways to sabotage their services during the service encounter. Service sabotage can take place in different forms by deferent employees including Thrill Seekers, Apathetic, Customer Revengers, and Money Grabbers [7,80]. Managers need to be aware that what constitutes sabotage in the workplace is not in isolation from workplace characteristics therefore, understanding and acknowledging it can contribute to the sustainability of the organization.

\section{Limitations and Pathway for Future Studies}

Notwithstanding the study's substantive contributions, it has some limitations. Primarily this study is a correlational attempt however, an experimental study can investigate cause and effect relationships between SS and each construct (characteristics of workplace/servicescape/ambiance). This is not only a limitation, it is also a suggestion for future studies. Furthermore, the analysis and discussions presented herein are based on the much smaller sample (five-star and four-star hotels) and future studies may investigate employees' service sabotage behaviors in other accommodation sectors as well as tourism subsectors with the application of a comparative study to draw a holistic picture.

Author Contributions: Conceptualization, H.A. and S.A.; methodology, F.S.; software, F.S. and B.P.; validation, H.A. and F.S.; survey, S.A.; data curation, H.A. and F.S.; writing-review and editing, H.A., A.S.; project administration, S.A.; supervision, B.P. and A.S. All authors have read and agreed to the published version of the manuscript.

Funding: This research received no external funding.

Data Availability Statement: The data presented in this study are available on request from the corresponding author.

Conflicts of Interest: The authors declare no conflict of interest.

\section{References}

1. Kwak, H.; McNeeley, S.; Kim, S.-H. Emotional Labor, Role Characteristics, and Police Officer Burnout in South Korea: The Mediating Effect of Emotional Dissonance. Police Q. 2018, 21, 223-249. [CrossRef]

2. Mayer, D.M.; Kuenzi, M.; Greenbaum, R.; Bardes, M.; Salvador, R. (Bombie) How low does ethical leadership flow? Test of a trickle-down model. Organ. Behav. Hum. Decis. Process. 2009, 108, 1-13. [CrossRef]

3. Lee, J.; Ok, C.M. Understanding hotel employees' service sabotage: Emotional labor perspective based on conservation of resources theory. Int. J. Hosp. Manag. 2014, 36, 176-187. [CrossRef]

4. Gunn, C.A.; Var, T. Policy. In Tourism Planning; Gunn, C.A., Var, T., Eds.; Routledge: New York, NY, USA, 2002; pp. 105-120; ISBN 9781003061656.

5. Hightower, R.; Brady, M.K.; Baker, T.L. Investigating the role of the physical environment in hedonic service consumption: An exploratory study of sporting events. J. Bus. Res. 2002, 55, 697-707. [CrossRef]

6. Yeh, C.M. Tourism Involvement, Work Engagement And Job Satisfaction Among Frontline Hotel Employees. Ann. Tour. Res. 2013, 42, 214-239. [CrossRef]

7. Harris, L.C.; Ogbonna, E. Service sabotage: The dark side of service dynamics. Bus. Horiz. 2009, 52, 325-335. [CrossRef]

8. Xu, S.T.; Cao, Z.C.; Huo, Y. Antecedents and outcomes of emotional labour in hospitality and tourism: A meta-analysis. Tour. Manag. 2020, 79, 104099. [CrossRef]

9. Grandey, A.A.; Melloy, R.C. The state of the heart: Emotional labor as emotion regulation reviewed and revised. J. Occup. Health Psychol. 2017, 22, 407-422. [CrossRef] [PubMed]

10. Bharathi, K.; Sudha, S. Store Ambiance Influence on Consumer Impulsive Buying Behavior towards Apparel: S-O-R Model. Indian J. Public Heal. Res. Dev. 2017, 8, 140. [CrossRef] 
11. Schreuder, E.; van Erp, J.; Toet, A.; Kallen, V.L. Emotional Responses to Multisensory Environmental Stimuli. SAGE Open 2016, 6, 215824401663059. [CrossRef]

12. Jani, D.; Han, H. Influence of environmental stimuli on hotel customer emotional loyalty response: Testing the moderating effect of the big five personality factors. Int. J. Hosp. Manag. 2015, 44, 48-57. [CrossRef]

13. Morrin, M.; Chebat, J.-C. Person-Place Congruency. J. Serv. Res. 2005, 8, 181-191. [CrossRef]

14. Morrison, M.; Gan, S.; Dubelaar, C.; Oppewal, H. In-store music and aroma influences on shopper behavior and satisfaction. J. Bus. Res. 2011, 64, 558-564. [CrossRef]

15. So, K.K.F.; Kim, H.; Oh, H. What Makes Airbnb Experiences Enjoyable? The Effects of Environmental Stimuli on Perceived Enjoyment and Repurchase Intention. J. Travel Res. 2020, 004728752092124. [CrossRef]

16. Ryu, K.; Jang, S.S. The Effect of Environmental Perceptions on Behavioral Intentions Through Emotions: The Case of Upscale Restaurants. J. Hosp. Tour. Res. 2007, 31, 56-72. [CrossRef]

17. Russell, J.A.; Mehrabian, A. Evidence for a three-factor theory of emotions. J. Res. Pers. 1977, 11, 273-294. [CrossRef]

18. Humborstad, S.I.W.; Humborstad, B.; Whitfield, R. Burnout and Service Employees' Willingness to Deliver Quality Service. J. Hum. Resour. Hosp. Tour. 2007, 7, 45-64. [CrossRef]

19. Mehrabian, A.; Russell, J.A. An Approach to Environmental Psychology; The MIT Press: Cambridge, MA, USA, 1974; ISBN 0262130904 .

20. Steg, L.; Bolderdijk, J.W.; Keizer, K.; Perlaviciute, G. An Integrated Framework for Encouraging Pro-environmental Behaviour: The role of values, situational factors and goals. J. Environ. Psychol. 2014, 38, 104-115. [CrossRef]

21. Reimer, A.; Kuehn, R. The impact of servicescape on quality perception. Eur. J. Mark. 2005, 39, 785-808. [CrossRef]

22. Bakker, I.; van der Voordt, T.; Vink, P.; de Boon, J. Pleasure, Arousal, Dominance: Mehrabian and Russell revisited. Curr. Psychol. 2014, 33, 405-421. [CrossRef]

23. Bitner, M.J. Servicescapes: The Impact of Physical Surroundings on Customers and Employees. J. Mark. 1992, 56, 57. [CrossRef]

24. d'Astous, A. Irritating Aspects of the Shopping Environment. J. Bus. Res. 2000, 49, 149-156. [CrossRef]

25. Durna, U.; Dedeoglu, B.B.; Balikçioglu, S. The role of servicescape and image perceptions of customers on behavioral intentions in the hotel industry. Int. J. Contemp. Hosp. Manag. 2015, 27, 1728-1748. [CrossRef]

26. Lee, T.J. Role of hotel design in enhancing destination branding. Ann. Tour. Res. 2011, 38, 708-711. [CrossRef]

27. Errajaa, K.; Legohérel, P.; Daucé, B. Immersion and emotional reactions to the ambiance of a multiservice space: The role of perceived congruence between odor and brand image. J. Retail. Consum. Serv. 2018, 40, 100-108. [CrossRef]

28. Sun, L.-Y.; Pan, W. HR practices perceptions, emotional exhaustion, and work outcomes: A conservation-of-resources theory in the Chinese context. Hum. Resour. Dev. Q. 2008, 19, 55-74. [CrossRef]

29. Heung, V.C.S.; Gu, T. Influence of restaurant atmospherics on patron satisfaction and behavioral intentions. Int. J. Hosp. Manag. 2012, 31, 1167-1177. [CrossRef]

30. Ryu, K.; Shawn Jang, S. DINESCAPE: A Scale for Customers' Perception of Dining Environments. J. Foodserv. Bus. Res. 2008, 11, 2-22. [CrossRef]

31. Liu, Y.; Jang, S. The effects of dining atmospherics: An extended Mehrabian-Russell model. Int. J. Hosp. Manag. 2009, 28, 494-503. [CrossRef]

32. Turley, L.; Milliman, R.E. Atmospheric Effects on Shopping Behavior. J. Bus. Res. 2000, 49, 193-211. [CrossRef]

33. Grandey, A.A. Emotional regulation in the workplace: A new way to conceptualize emotional labor. J. Occup. Health Psychol. 2000, 5, 95-110. [CrossRef] [PubMed]

34. Mayer, J.D.; Salovey, P.; Caruso, D.R.; Cherkasskiy, L. Emotional Intelligence. In The Cambridge Handbook of Intelligence; Sternberg, R.J., Kaufman, S.B., Eds.; Cambridge Handbooks in Psychology; Cambridge University Press: Cambridge, UK, 2011 ; pp. 528-549.

35. Giardini, A.; Frese, M. Linking service employees' emotional competence to customer satisfaction: A multilevel approach. J. Organ. Behav. 2008, 29, 155-170. [CrossRef]

36. Mayer, J.D.; Salovey, P. The intelligence of emotional intelligence. Intelligence 1993, 17, 433-442. [CrossRef]

37. Lechner, A.T.; Paul, M. Is this smile for real? The role of affect and thinking style in customer perceptions of frontline employee emotion authenticity. J. Bus. Res. 2019, 94, 195-208. [CrossRef]

38. Cheung, F.Y.-L.; Tang, C.S.-K. Quality of Work Life as a Mediator Between Emotional Labor and Work Family Interference. J. Bus. Psychol. 2009, 24, 245-255. [CrossRef]

39. Gross, J.J. Antecedent- and response-focused emotion regulation: Divergent consequences for experience, expression, and physiology. J. Pers. Soc. Psychol. 1998, 74, 224-237. [CrossRef]

40. Hobfoll, S.E. Conservation of resources: A new attempt at conceptualizing stress. Am. Psychol. 1989, 44, 513-524. [CrossRef] [PubMed]

41. O'Brien, E.; Linehan, C. Problematizing the authentic self in conceptualizations of emotional dissonance. Hum. Relations 2019, 72, 1530-1556. [CrossRef]

42. Mayer, J.D.; Salovey, P. What is emotional intelligence? In Emotional Development and Emotional Intelligence: Implications for Educators; Salovey, P., Sluyte, D., Eds.; Basic Books: New York, NY, USA, 1997; pp. 3-31; ISBN 9780465095872.

43. Andela, M.; Truchot, D.; Van der Doef, M. Job stressors and burnout in hospitals: The mediating role of emotional dissonance. Int. J. Stress Manag. 2016, 23, 298-317. [CrossRef] 
44. Cheung, F.Y.-L.; Cheung, R.Y.-H. Effect of Emotional Dissonance on Organizational Citizenship Behavior: Testing the StressorStrain-Outcome Model. J. Psychol. 2013, 147, 89-103. [CrossRef]

45. Zapf, D.; Vogt, C.; Seifert, C.; Mertini, H.; Isic, A. Emotion Work as a Source of Stress: The Concept and Development of an Instrument. Eur. J. Work Organ. Psychol. 1999, 8, 371-400. [CrossRef]

46. Lin, I.Y. Evaluating a servicescape: The effect of cognition and emotion. Int. J. Hosp. Manag. 2004, 23, 163-178. [CrossRef]

47. Westman, M.; Hobfoll, S.E.; Chen, S.; Davidson, O.B.; Laski, S. Organizational stress through the lens of Conservation Of Resources (COR) Theory. In Research in Occupational Stress and Well-Being; Sonnentag, S., Perrewé, P.L., Ganster, D.C., Eds.; Emerald (MCB UP): Bingley, UK, 2004; pp. 167-220. ISBN 1479-3555.

48. Trigg, D. Furniture Music, Hotel Lobbies, and Banality. Sp. Cult. 2006, 9, 418-428. [CrossRef]

49. Choi, B.C.K.; Pak, A.W.P. A catalog of biases in questionnaires. Prev. Chronic Dis. 2005, 2, 1-13.

50. Bryman, A. Social Research Methods, 5th ed.; Oxford University Press: Oxford, UK, 2016; ISBN 9780192529497.

51. Lavrakas, P. Encyclopedia of Survey Research Methods; Sage Publications, Inc.: Thousand Oaks, CA, USA, 2008; ISBN 9781412918084.

52. Harris, L.C.; Ogbonna, E. Exploring Service Sabotage. J. Serv. Res. 2002, 4, 163-183. [CrossRef]

53. Bagozzi, R.P.; Yi, Y. On the evaluation of structural equation models. J. Acad. Mark. Sci. 1988, 16, 74-94. [CrossRef]

54. Straub, D.W. Validating Instruments in MIS Research. MIS Q. 1989, 13, 147. [CrossRef]

55. Milliman, R.E. The Influence of Background Music on the Behavior of Restaurant Patrons. J. Consum. Res. 1986, 13, 286. [CrossRef]

56. Wong, C.-S.; Law, K.S. The effects of leader and follower emotional intelligence on performance and attitude. Leadersh. Q. 2002, 13, 243-274. [CrossRef]

57. Chu, K.H.-L.; Murrmann, S.K. Development and validation of the hospitality emotional labor scale. Tour. Manag. 2006, 27, 1181-1191. [CrossRef]

58. Harris, L.C.; Ogbonna, E. Service Sabotage: A Study of Antecedents and Consequences. J. Acad. Mark. Sci. 2006, 34, 543-558. [CrossRef]

59. Kruml, S.M.; Geddes, D. Exploring the Dimensions of Emotional Labor. Manag. Commun. Q. 2000, 14, 8-49. [CrossRef]

60. Johnson, H.-A.M.; Spector, P.E. Service with a smile: Do emotional intelligence, gender, and autonomy moderate the emotional labor process? J. Occup. Health Psychol. 2007, 12, 319-333. [CrossRef] [PubMed]

61. Sposito, V.A.; Hand, M.L.; Skarpness, B. On the efficiency of using the sample kurtosis in selecting optimal lpestimators. Commun. Stat. Comput. 1983, 12, 265-272. [CrossRef]

62. Voorhees, C.M.; Brady, M.K.; Calantone, R.; Ramirez, E. Discriminant validity testing in marketing: An analysis, causes for concern, and proposed remedies. J. Acad. Mark. Sci. 2016, 44, 119-134. [CrossRef]

63. Hayes, A.F. Introduction to Mediation, Moderation, and Conditional Process Analysis, 2nd ed.; The Guilford Press: New York, NY, USA; London, UK, 2017; ISBN 978-1-60918-230-4.

64. Podsakoff, P.M.; MacKenzie, S.B.; Lee, J.-Y.; Podsakoff, N.P. Common method biases in behavioral research: A critical review of the literature and recommended remedies. J. Appl. Psychol. 2003, 88, 879-903. [CrossRef]

65. Biggers, T.; Pryor, B. Attitude Change. Personal. Soc. Psychol. Bull. 1982, 8, 94-99. [CrossRef]

66. Vodanovich, S.J. Psychometric Measures of Boredom: A Review of the Literature. J. Psychol. 2003, 137, 569-595. [CrossRef]

67. Franz, G. Space, color, and perceived qualities of indoor environments. In Proceedings of the Environment, Health and Sustainable Development (IAPS 19), Alexandria, Egypt, 11-16 September 2006; pp. 1-8.

68. Mikolajczak, M.; Luminet, O.; Leroy, C.; Roy, E. Psychometric Properties of the Trait Emotional Intelligence Questionnaire: Factor Structure, Reliability, Construct, and Incremental Validity in a French-Speaking Population. J. Pers. Assess. 2007, 88, 338-353. [CrossRef]

69. Mikolajczak, M.; Roy, E.; Luminet, O.; Fillée, C.; de Timary, P. The moderating impact of emotional intelligence on free cortisol responses to stress. Psychoneuroendocrinology 2007, 32, 1000-1012. [CrossRef]

70. Härtel, C.E.J.; Zerbe, W.J.; Ashkanasy, N.M. Organizational behavior: An emotions perspective. In Emotions in Organizational Behavior; Hartel, C., Ashkanasy, N.M., Zerbe, W., Eds.; Psychology Press—Erlbaum: New York, NY, USA, 2005; pp. 1-8; ISBN 9781410611895.

71. Liu, Y.; Perrewé, P.L. The Role of Emotion in Employee Counterproductive Work Behavior: Integrating the Psychoevolutionary and Constructivist Perspective. In Emotions in Organizational Behavior; Hartel, C., Ashkanasy, N.M., Zerbe, W., Eds.; Psychology Press-Erlbaum: New York, NY, USA, 2005; pp. 67-86; ISBN 9781410611895.

72. Jani, D.; Han, H. Testing the Moderation Effect of Hotel Ambience on the Relationships Among Social Comparison, Affect, Satisfaction, and Behavioral Intentions. J. Travel Tour. Mark. 2014, 31, 731-746. [CrossRef]

73. Kotler, P. The Major Tasks of Marketing Management. J. Mark. 1973, 37, 42-49. [CrossRef]

74. Mount, M.; Ilies, R.; Johnson, E. Relationship of personality traits and counterproductive work behaviors: The mediating effects of job satisfaction. Pers. Psychol. 2006, 59, 591-622. [CrossRef]

75. Flaherty, S.; Moss, S.A. The Impact of Personality and Team Context on the Relationship Between Workplace Injustice and Counterproductive Work Behavior. J. Appl. Soc. Psychol. 2007, 37, 2549-2575. [CrossRef]

76. Shao, R.; Skarlicki, D.P. Service Employees' Reactions to Mistreatment by Customers: A Comparison Between North America and East Asia. Pers. Psychol. 2014, 67, 23-59. [CrossRef]

77. Cho, S.; Johanson, M.M. Organizational Citizenship Behavior and Employee Performance: A Moderating Effect of Work Status in Restaurant Employees. J. Hosp. Tour. Res. 2008, 32, 307-326. [CrossRef] 
78. Hu, H.H.H.S.; Lai, H.S.H.; King, B. Restaurant Employee Service Sabotage and Customer Deviant Behaviors: The Moderating Role of Corporate Reputation. J. Hosp. Tour. Res. 2020, 44, 1126-1152. [CrossRef]

79. Iszatt-White, M. Leadership as Emotional Labour: The Effortful Accomplishment of Valuing Practices. Leadership 2009, 5, 447-467. [CrossRef]

80. Southey, K. To fight, sabotage or steal: Are all forms of employee misbehaviour created equal? Int. J. Manpow. 2016, 37, 1067-1084. [CrossRef] 